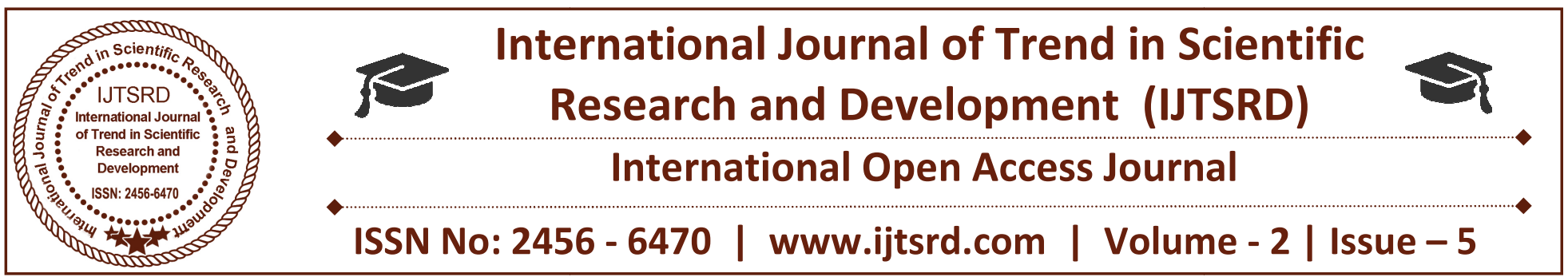

\title{
Analysis Communication Process in Mcdonalds
}

\author{
Surbhi Suryavanshi \\ Department of Law, Indore Institute of Law, \\ Indore, Madhya Pradesh, India
}

\section{INTRODUCTION}

Communication is the way toward sending and getting messages through verbal or nonverbal means, including speech, or oral communication; composing and graphical portrayals, for example, info graphics, maps, and diagrams and signs, signs, and conduct. All the more essentially, communication is said to be the creation and trade of significance. McDonalds is the one of the main eatery networks on the planet, contacting the lives of people each day, they enhanced their quality of items and administrations with the time. In the past McDonalds does not have drive through and 24 hour administrations. Every one of them are open for late evenings. McDonalds primarily offers ground sirloin sandwiches, cheddar burgers, chicken items, French fries, breakfast things, soda pops, drain shakes, and deserts.

The McDonald's is one of the best-known multinational companies in the world. The fast food chain originates from the United States, where its parent company is based in Chicago. It is responsible for overseeing other headquarters nationally. The feed chain has more than 46 million people every day worldwide, more than the Spanish population. In the U.S., McDonald's owns more than $43 \%$ market share of fast food. The institution is also established in public places: airports, gas stations, shopping malls, train stations, amusement parks etc.

In 1940, the brothers Richard and Maurice McDonald chose to create the organization, presenting drive-thru food eight years after the fact. Be that as it may, his jump was in 1955 with the principal establishment, accepted by the official Ray Kroc.

\section{Interpersonal Communication}

Interpersonal communication is communication between two people. Some books like to refer to it as face-to-face communication, or communication when people are physically present with each other. In the interpersonal communication, we research on communication between the manager and staff members and also research the communication between customers and staff. ${ }^{1}$

\section{Communication between Manager and Staff}

When we research on McDonalds, it was discovered that all the eatery representatives are from different countries with different foundations. Representatives are accomplished and experienced. In any case, there are a few downsides in the communication between chiefs and the staff members. This downside is a languages barrier. Since the greater parts of the workers have originated from different countries, they talk different languages from each other. The gatherings led at McDonalds include administrators and workers conveying to discover the issues being looked at the division.

\section{Communication between Staff Members and Customers}

In this McDonald, mostly women are in the front and attend the new customers. The woman who is attending customer is very friendly and has good communication. All staff members are trained well before to communicate effectively. To communicate well, it is necessary to talk politely and use gestures to convey meaning .Team member give consumer loyalty through good client service. In the interview

\footnotetext{
${ }^{1}$ https://www.ukessays.com/essays/management/analy sing-the-communication-process-in-mcdonaldsmanagement-essay.php
} 
With the manager we asked some general questions about the McDonald have to gain some knowledge about the Organization with in the McDonald's. Organization communication is divided into two major parts which is as follow ${ }^{2}$ :-

$>$ Internal organization communication

$>$ External organization communication

\section{Internal Organization Communication Organization Goal:}

Essential goal of McDonalds based on yearly and they for the most part consider about the customer service. It likewise incorporates the misuse of the McDonalds. They likewise need to give the customers quick service they need to diminish their loss as much they can so. The few goals of McDonalds are as per the following

$>$ CSO (Customer satisfaction objective)-100 \%( McDonalds main goal is to give customer full satisfaction)

$>$ KVS (kitchen video system)-35\% this is the time taken to make burgers and other fast food products in the kitchen area after every order and it's normally 35 seconds.

$>$ Labor-26\% McDonalds want to save the labor up to $26 \%$ as they had given last year.

$>$ Refunds- below $0.10 \%$ ( company wants to give less refund to the customer to earn more profit ${ }^{3}$

\section{Information Flow in the Organization}

In the organization information flows from higher level to lower level as every information for instance a launch of new product or changing of rules firstly comes to restaurant manager and after that he pass on the information to the middle level manager or we can call them as shift manager and the shift manager pass on the information to the crew members by a team meeting or putting the information on the crew room so that everybody can read that information. And especially when a new product is launching ${ }^{4}$.

\footnotetext{
${ }^{2}$ https://www.ukessays.com/essays/management/analy sing-the-communication-process-in-mcdonaldsmanagement-essay.php ${ }^{3}$ https://www.ukessays.com/essays/management/analy sing-the-communication-process-in-mcdonalds -management-essay.php ${ }^{4}$ https://www.ukessays.com/essays/management/analy sing-the-communication-process-in-mcdonaldsmanagement-
}

\section{External Communication Dealing With Customers:}

This is the continuous piece of the communication in the McDonalds and which is to be utilized 24 hours to serve the customers. What's more, it is utilized to deal with the issues of customers too. In the McDonalds there is a particular pattern to manage the customers which is depicted by the chief of McDonalds. In this piece of communication is utilized to manage each customer and this pattern is composed is additionally composed in each request taking register and this pattern is isolated into part and those are as per the following:-

1. First smile and greet to customer.

2. Take the order correctly by repeating the order to the customer

3. At last say enjoy your meal and good bye.

\section{Communication with Stakeholders}

In this organization mainly restaurant manager and senior assistant manager communicate with the stakeholders and the organization like McDonalds plays a vital role in communication with the stakeholders because they have to always to be ready to give the customer a better service and not to get a stock out of anything which is used within the organization. ${ }^{5}$

\section{Team Communication}

\section{Team Goal:}

Team goals are extremely simple make an arrangement and afterward tail it. In McDonalds teams are prepared well to take after the example. Leader of the team requests that the team execute an arrangement and the entire team takes after the arrangement. All team members do work as indicated by planning.

\section{Roles:}

In a team every member has a part to fulfill the requirements of the team. In McDonalds there is a branch manager, team pioneer or move manager. Presently there are three counters to serve the customers. On counter 1 there are three members working, on counter 2 there are two members and team pioneer working and on counter 3 again three

\footnotetext{
${ }^{5}$ https://www.ukessays.com/essays/management/analy sing-the-communication-process-in-mcdonaldsmanagement-essay.php
} 
members are working. Presently cleaning team is there to do the cleanings and furthermore to help the members of the team in the event that anybody requires help and it comprises of two members. So the information stream is from the two sides that are descending to upward and furthermore upward to descending.

\section{Branch Manager}

1. Team Leader It

2. Counter Team 1 Counter Team 2 Counter Team 3

3. Cleaning Team

\section{Conculsion}

McDonald is one of the most well-known fast food restaurants in the world. It is so popular that it sells seventy five hamburgers every second and is shocking also the world's largest toy distributor. According to this research, we came up with the conclusion that due to the different different background and culture of the stay members and managers, I acquisition that there is languages barrier in communication process because of different background and culture of stay member. I found that the level of satisfaction depends on the quality of services a customer receives. .Both Men and women deal with the customers because they are trained well before they join the staff. Every staff member of McDonald they have to communicate accurately to satisfy the customers need. In this research work I observed that Internal and External environment play very important role to run the business and earn profit. Without proper communication, organization cannot achieve the goals. For achieving this goal every individual employees has to contribute to the main organization goal. Manger should do proper meeting with employees to overcome communication gap in the organization .They must take opinions of employees before implementing a new rule in the organization.

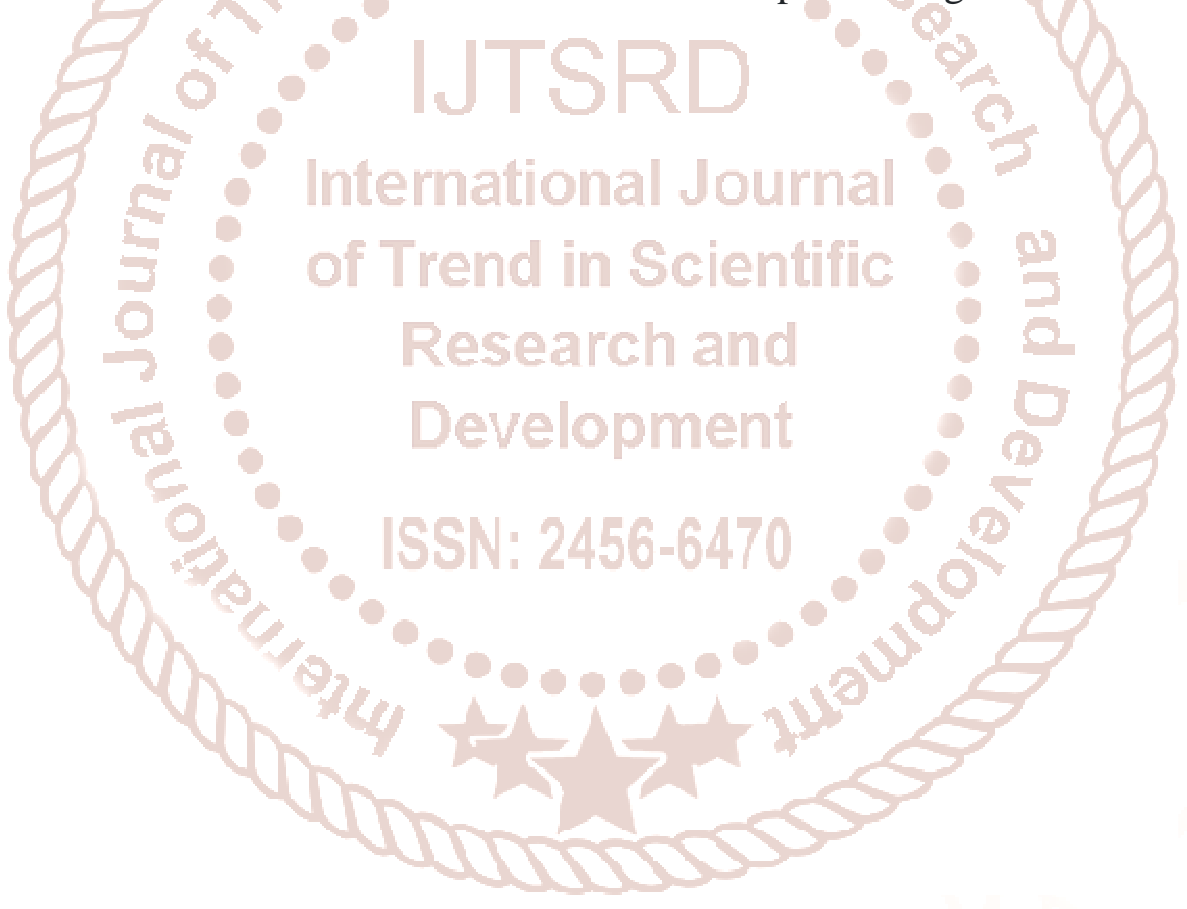

